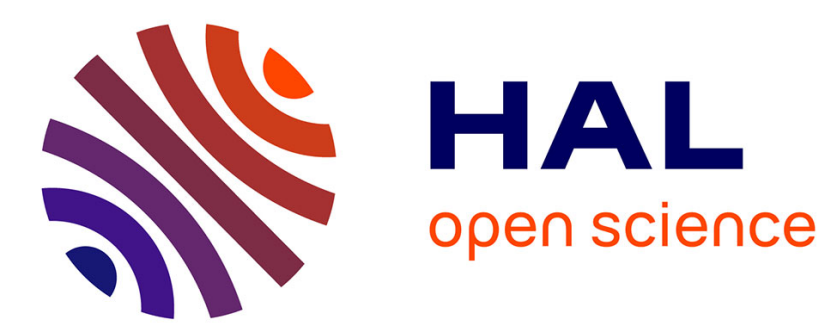

\title{
On the benefits of correcting brightness and contrast in global digital image correlation: Monitoring cracks during curing and drying of a refractory castable
} V F Sciuti, R B Canto, J. Neggers, François Hild

\section{- To cite this version:}

V F Sciuti, R B Canto, J. Neggers, François Hild. On the benefits of correcting brightness and contrast in global digital image correlation: Monitoring cracks during curing and drying of a refractory castable. Optics and Lasers in Engineering, 2020, 136, pp.106316. 10.1016/j.optlaseng.2020.106316 . hal-02910810

\author{
HAL Id: hal-02910810 \\ https://hal.science/hal-02910810
}

Submitted on 3 Aug 2020

HAL is a multi-disciplinary open access archive for the deposit and dissemination of scientific research documents, whether they are published or not. The documents may come from teaching and research institutions in France or abroad, or from public or private research centers.
L'archive ouverte pluridisciplinaire HAL, est destinée au dépôt et à la diffusion de documents scientifiques de niveau recherche, publiés ou non, émanant des établissements d'enseignement et de recherche français ou étrangers, des laboratoires publics ou privés. 


\title{
On the benefits of correcting brightness and contrast in global digital image correlation: Monitoring cracks during curing and drying of a refractory castable
}

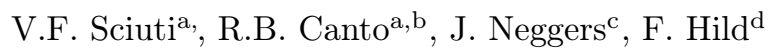 \\ ${ }^{a}$ Federal University of São Carlos (UFSCar) \\ Graduate Program in Materials Science and Engineering \\ Rodovia Washington Luis, km 235, 13565-905, São Carlos-SP, Brazil \\ ${ }^{b}$ Federal University of São Carlos (UFSCar) \\ Department of Materials Engineering (DEMa) \\ Rodovia Washington Luis, km 235, 13565-905, São Carlos-SP, Brazil \\ ${ }^{c}$ Université Paris-Saclay, CentraleSupélec, CNRS \\ Laboratoire de Mécanique des Sols, Structures et Matériaux, Gif-sur-Yvette, France \\ ${ }^{d}$ Université Paris-Saclay, ENS Paris-Saclay, CNRS \\ LMT - Laboratoire de Mécanique et Technologie, Gif-sur-Yvette, France
}

\begin{abstract}
The gray level conservation is the underlying hypothesis of Digital Image Correlation (DIC). However, it may be challenging to enforce in some experimental configurations. Brightness and contrast corrections (BCCs) may be added to the registration procedure. Different types of BCCs were implemented for global DIC, and their benefits were analyzed for localized and diffuse sources of brightness changes. As a case study to apply BCCs, a refractory castable was placed inside a climatic chamber, and cracks were generated due to localized expansions during its curing and drying. To choose the best BCC for this case, two sets of images were considered. The first one allowed the noise floor levels to be evaluated. The second one dealt with the development of a crack network. The BCCs significantly reduced gray level residuals enabling cracks with small openings to be detected. The coarse discretization was effective in correcting lighting changes and avoided its coupling with the measured kinematic fields and other local phenomena.
\end{abstract}

Keywords: Crack opening displacement, global digital image correlation, brightness and contrast, gray level residuals, uncertainty quantification 


\section{Introduction}

Digital Image Correlation (DIC) registers images to measure displacement 2 fields on specimen surfaces $[1,2]$ and in the bulk via digital volume correlation $[3, \quad 3$ 4]. The displacements may, for instance, be caused by mechanical loads [5] or thermal histories [6]. The images can be 2D [7], generated not only by visible

light but also by infrared radiation [8,9] or electron beams as in Scanning Electron Microscopy (SEM) [10, 11]. They can also be 3D volumes reconstructed from tomographic scans $[12,13]$.

Two advantages of DIC over conventional extensometry are highlighted. It provides full-field measurements (instead of point-data), and no physical contact is needed between the material and the probe $[2,5]$. The first advantage represents an increase of the amount of gathered information. For example, displacement fields of entire surfaces are measured, and not only the crack mouth opening displacement during fracture tests. The correlation between measured fields and close-form solutions can be used to calibrate fracture mechanics parameters $[14,15]$. The second advantage enables the technique to be applied to soft materials $[16,17]$ or at high temperatures $[6,18]$.

Independently of the image modality, the central hypothesis in DIC tech- ${ }_{18}$ niques is the gray level conservation when the reference and deformed images are matched (i.e., through the determination of the optical flow [19]). Many phenomena can disturb the optical flow, i.e., they can change the gray levels of pixels. Some of them are due to lighting of the experiment [20, 21, 2, 22, 23], drifts of electron beams in SEMs [11, 24], and variations of the refractive index caused by temperature gradients between the imaging device and the sample $[18,25]$. The use of lighting with band pass filters $[26,27,18]$ mitigated radiation effects due to high temperatures, or working at shorter wavelengths [14] as suggested by Planck's law [28]. Besides the afore-mentioned hardware solutions, software solutions were also implemented very early on $[20,2]$. It is worth noting that oftentimes these corrections are uniform over each interrogation window $[21,22,23]$ and linear with respect to the reference image. The (n) 
Zero-Normalized Cross-Correlation (ZNCC) criterion is one of the most popular $\quad \mathbf{3 1}_{\mathbf{1}}$ corrections $[29,21,2,22,23]$. For instance, this type of correction was used to 32 investigate crack propagation in rocks [30]. Another known correction is a gray 3 level average to minimize high temperature effects [31].

Gray level corrections were also introduced in global DIC via brightness and $\quad 35$ contrast field changes [32]. Some specific cases used the gray level corrections, $\quad 36$ for example, DIC analyses of infrared pictures [8, 9], and distortion corrections $\quad 37$ of infrared lenses [33]. Tests performed at temperatures up to $1860^{\circ} \mathrm{C}$, for which gray level inversions occurred, can also be monitored via global DIC [28]. Such procedures were extended to global stereocorrelation to account for illumination variations [34], in hybrid multiview correlation to register images of different modalities [35]. In digital volume correlation, the determination of metric and topological differences on 3D woven composite samples also required gray level corrections [36]. Similarly, thanks to such corrections, the gap between modeling and analysis could be bridged for 3D woven composites [37].

To study the effect of brightness and contrast corrections in the results of global DIC, the monitoring of cracks during curing and drying of an $\mathrm{MgO}$ containing refractory castable was chosen as a case study. The conservation of gray levels was disturbed by temperature and air humidity (processing conditions) because they alter the refractive index of air [38]. In the field of refractory materials, DIC has been applied to their characterization [39, 40, 41, 14], and to the detection of initiation and propagation of cracks [42, 43]. For instance, DIC was used to analyze drying of mortar [44], and the crack pattern during curing and drying of refractory castables [45]. In the present work, small corrections in gray levels are proposed since the temperature levels remained less than $60{ }^{\circ} \mathrm{C}$ but the duration of the test was very long (i.e., $60 \mathrm{~h}$ ). The corrections are based on brightness relaxation, contrast relaxation, or both, to reduce the changes in gray level residuals.

As the case study consists in monitoring cracks in a cube made of refrac- 59 tory castable put inside a climatic chamber, there are two sources of gray level 60 variations, namely, the experimental environment (i.e., temperature and hu- ${ }_{61}$ 
midity) and the development of crack networks. The corrections were applied 62 to two different sets of images. The first set (set \#1) used ten images acquired ${ }_{63}$ before crack initiation and investigated the influence of the environment. The ${ }_{64}$ second set (set \#2) used all the images of the experiment to account for how ${ }_{65}$ the corrections affect the quantification of cracks. The outline of the paper is 66 as follows. First, the material, the experiment and the enriched DIC framework $\quad 67$ are presented. Second, uncertainty quantifications are performed with set \#1 $\mathbf{6 8}$ for two different discretizations and three different corrections. Third, set $\# 2 \quad 69$ is studied by varying the same set of parameters. Their effect on the gray level 70 residuals and maximum principal strain data will be assessed.

\section{Material and Methods}

\subsection{Refractory castable}

The refractory castable studied herein belongs to the group of high alumina $\quad \mathbf{7 4}_{\mathbf{7 4}}$ refractories [46], and it contains 6 wt.\% of caustic magnesia $\left(\mathrm{d}_{90}<33 \mu \mathrm{m}\right) . \quad{ }_{\mathbf{7 5}}$ The castable was formulated following the Alfred packing model with $q=0.26$. $\quad$ 76 The raw materials were tabular alumina (Almatis, Germany) and reactive alu- $\quad 77$ minas CL370 and CT3000SG. A polycarboxylate ether-based dispersing agent $\quad 78$ (Castament ${ }^{\circledR}$ FS60, BASF, Germany) was selected. The amount of water was ${ }_{79}$ adjusted to provide $80 \%$ of the initial flow under vibration [47]. The $\mathrm{Al}_{2} \mathrm{O}_{3}-\mathrm{MgO} \quad \mathbf{8 0}$ castable formulation is summarized in Table 1. 
Table 1: Composition of the studied $\mathrm{Al}_{2} \mathrm{O}_{3}-\mathrm{MgO}$ based castable

\begin{tabular}{|c|c|}
\hline Raw materials & [wt.\%] \\
\hline \hline Tabular alumina $(d \leq 6 \mathrm{~mm})$ & 81 \\
\hline Tabular alumina $(d<45 \mathrm{~mm})$ & 6 \\
\hline Reactive alumina $(\mathrm{CL} 370)$ & 2 \\
\hline Reactive alumina (CT3000SG) & 5 \\
\hline Caustic magnesia (SA $\left.=24.57 \mathrm{~m}^{2} \mathrm{~g}^{-1}\right)$ & 6 \\
\hline Water & 5.1 \\
\hline Dispersant & 0.2 \\
\hline
\end{tabular}

A cubic specimen of size $\approx 70 \times 70 \times 70 \mathrm{~mm}^{3}$ was produced as follows: $\quad \mathbf{8 2}$

- the castable was homogenized for $10 \mathrm{~min}$ in a rheometer; $\quad \mathbf{8 3}$

- the mix was cast under vibration into a silicone mold with cavity dimen- $\quad \mathbf{8 4}$ sions of $70 \times 70 \times 70 \mathrm{~mm}^{3} ;$

- the specimen and mold were stored in an in-house developed climatic $\mathbf{8 6}$ chamber for $3 \mathrm{~h}$ at $50^{\circ} \mathrm{C}$ and $50 \%$ of air humidity before been unmolded; $\quad{ }_{\mathbf{8 7}}$

- a face was painted using only black paint speckled on the light and mat $\mathbf{8 8}$ hued surfaces to provide contrast for DIC purposes. More details about the specimen production and the climatic chamber used in 90 the experimental set-up can be found in Ref. [48].

\subsection{Image acquisition 92}

The hardware parameters of the optical setup are reported in Table 2. An ${ }_{93}$ exposure time of $3.2 \mathrm{~s}$ was chosen to perform a physical average of the intensity $\quad 94$ acquired by each pixel [49]. LED lights were put inside the climatic chamber $\quad 95$ for lighting purposes. 
Table 2: DIC hardware parameters

\begin{tabular}{|l|l|}
\hline \hline Camera & CANON T5 Rebel \\
Definition & $3529 \times 5296$ pixels (Bayer pixels) \\
Color filter & Bayer \\
Gray Levels amplitude & $16 \mathrm{bits}$ \\
Lens & CANON 100-mm macro \\
Aperture & $f / 22$ \\
Field of view & $65 \times 65 \mathrm{~mm}^{2}$ \\
Image scale & $50 \mathrm{\mu m} /$ pixel \\
Stand-off distance & $102 \mathrm{~cm}$ \\
Image acquisition rate & 6 fpmin (set \#1) and 2 fph (set \#2) \\
Exposure time & $3.2 \mathrm{~s}$ \\
Patterning technique & sprayed black paint \\
Pattern feature size $\sharp$ & 4 pixels (B/W) \\
\hline \hline
\end{tabular}

$\sharp$ evaluated as full width at half maximum of autocorrelation function

The images were acquired as RAW files and then converted to gray scale 97 TIFF images using the Bayer filter [50]. The latter is an assembly of RGB 9 filters arranged as a mosaic with a proportion of $25 \%$ red, $50 \%$ green, and $25 \%$ 99 blue on the camera sensor. The conversion from RAW to TIFF was performed 100 as the average of one red, two green, and one blue levels, which reduces the ${ }_{101}$ image definition by a factor $2 \times 2$. The time interval between acquisitions was 102 $10 \mathrm{~s}$ for set $\# 1$ and $30 \mathrm{~min}$ for set $\# 2$ (i.e., $\approx 200$ images were acquired during ${ }_{103}$ the test).

\subsection{Gray Level Corrections in Global DIC}

Global DIC consists in performing registrations over the whole ROI (and ${ }_{106}$ not subdividing it into small interrogation windows). The first propositions ${ }_{107}$ were based upon spectral decompositions of the displacement field [51, 52]. ${ }_{108}$ Then, finite element discretizations were considered $[53,54,55]$. The sought ${ }_{109}$ 
displacement field is written as

$$
\mathbf{v}(\mathbf{x})=\sum_{i} v_{i} \mathbf{\Psi}_{i}(\mathbf{x})
$$

where $\boldsymbol{\Psi}_{i}(\mathbf{x})$ are, in the present case, finite element shape functions, and $v_{i}{ }^{111}$ nodal displacements. The deformed image corrected by such displacement fields ${ }_{112}$ becomes

$$
\widetilde{g}_{\{v\}}(\mathbf{x})=g\left(\mathbf{x}+v_{i} \boldsymbol{\Psi}_{i}(\mathbf{x})\right),
$$

where the column vector $\{v\}$ gathers all nodal displacements $v_{i}$. In global DIC, ${ }_{114}$ the gray level differences are globally minimized over the ROI

$$
\mathcal{T}_{g}(\{v\})=\left\|\widetilde{g}_{\{v\}}(\mathbf{x})-f(\mathbf{x})\right\|_{\mathrm{ROI}}^{2}
$$

such that the sought displacement is the argument that minimizes $\mathcal{T}_{g}(\{v\})$

$$
\{v\}_{\mathrm{DIC}}=\arg \min _{\{v\}} \mathcal{T}(\{v\}) .
$$

Such writing corresponds to a nonlinear least squares minimization. For in- ${ }_{117}$ stance, a Gauss-Newton scheme can be selected. Let us then consider small ${ }_{118}$ amplitudes of nodal displacement corrections $\delta v_{i}$, and Taylor expand $\widetilde{g}$ with ${ }_{119}$ respect to the current estimate of the nodal displacements $\{v\}$

$$
\begin{aligned}
\tilde{g}_{\{v\}}\left(\mathbf{x}+\delta v_{i} \mathbf{\Psi}_{i}(\mathbf{x})\right) & =\tilde{g}_{\{v\}}(\mathbf{x})+\nabla \tilde{g}_{\{v\}}(\mathbf{x}) \cdot \mathbf{\Psi}_{i}(\mathbf{x}) \delta v_{i}+\text { H.O.T. } \\
& \approx \tilde{g}_{\{v\}}(\mathbf{x})+\nabla \tilde{f}(\mathbf{x}) \cdot \mathbf{\Psi}_{i}(\mathbf{x}) \delta v_{i},
\end{aligned}
$$

where the additional assumption $\nabla \tilde{g}_{\{v\}}(\mathbf{x}) \approx \nabla \tilde{f}(\mathbf{x})$ was used. With such lin- ${ }^{121}$ earization, the approximated least squares functional is quadratic in terms of ${ }_{122}$ displacement corrections. Its minimization then leads to a linear system

$$
[\mathbf{H}]\{v\}=\{\mathbf{j}\},
$$

where $[\mathbf{H}]$ is the (symmetric semi-definite positive) Hessian, and $\{\mathbf{j}\}$ the righ- ${ }^{124}$ hand side term, whose components read

$$
\begin{aligned}
H_{i j} & =\sum_{\mathrm{ROI}}\left(\nabla \tilde{f}(\mathbf{x}) \cdot \mathbf{\Psi}_{i}(\mathbf{x})\right)\left(\nabla \tilde{f}(\mathbf{x}) \cdot \mathbf{\Psi}_{j}(\mathbf{x})\right) \\
j_{i} & =\sum_{\text {ROI }}\left(\nabla \tilde{f}(\mathbf{x}) \cdot \mathbf{\Psi}_{i}(\mathbf{x})\right) \rho_{\{v\}}(\mathbf{x})
\end{aligned}
$$


with

$$
\rho_{\{v\}}(\mathbf{x})=f(\mathbf{x})-\tilde{g}_{\{v\}}(\mathbf{x})
$$

the gray level residuals associated with the current estimate of the nodal dis- ${ }_{\mathbf{1 2 7}}$ placements $\{v\}$. Iteratively solving system of equations (6), the nodal dis- 128 placements and corrected image are updated. The procedure continues until a 129 convergence criterion is reached, namely, the maximum amplitude of the nodal $\quad \mathbf{1 3 0}$ displacement corrections becomes less than a selected threshold (i.e., $10^{-4} \mathrm{px} \quad{ }_{131}$ in the present case). 132

In the above-described procedure, gray level conservation was assumed dur- $\quad{ }_{\mathbf{1 3 3}}$ ing optical flow. If such hypothesis is no longer satisfied, the previous residuals $\quad 134$ $\rho_{\{v\}}(\mathbf{x})$ can still be lowered in a second step by considering brightness and 135 contrast corrections (with no changes in displacements)

$$
\rho_{b c c}(\mathbf{x})=\rho_{\{v\}}(\mathbf{x})+q(\mathbf{x}, f)
$$

where $q(\mathbf{x}, \mathbf{f})$ is the gray level correction field that depends on the pixel position $\quad{ }_{\mathbf{1 3 7}}$ $\mathbf{x}$, and the gray levels of $f$. In the present work, the first two terms are selected ${ }_{138}$

$$
q(\mathbf{x}, f) \approx b(\mathbf{x})+c(\mathbf{x}) f(\mathbf{x})
$$

and correspond to the brightness correction field $b$, and contrast correction field $\quad 139$ c. Such hypothesis leads to an affine model at the pixel level, which is commonly performed at the subset level in local DIC [20, 21, 2, 22, 23], yet generally not ${ }_{\mathbf{1 4 1}}$ written in this form. In the following, non uniform corrections are considered. 142 Various spatial approximations were proposed $[32,33,9,36]$. Finite element 14 discretizations were selected for the sake of simplicity and adaptability. As for ${ }_{\mathbf{1 4 4}}$ the displacement field, the two correction fields are written as

$$
b(\mathbf{x})=\sum_{k} b_{k} \theta_{k}(\mathbf{x}) \text { and } c(\mathbf{x})=\sum_{k} c_{k} \theta_{k}(\mathbf{x})
$$

where $\theta_{k}(\mathbf{x})$ are (scalar) finite element shape functions, $b_{k}$ nodal brightness and $c_{k}$ nodal contrast corrections. The latter ones are obtained by minimizing the $\mathbf{1 4 7}$ L2-norm of $\rho_{b c c}$ with respect to the column vector $\{\varsigma\}$ gathering all corrections $b_{k} \quad \mathbf{1 4 8}$ 
and $c_{k}$. In the present case, a standard least squares minimization is performed $\quad \mathbf{1 4 9}$ (i.e., no iterations are needed). From these estimates, a corrected reference $\mathbf{1 5 0}$ image $\hat{f}$ is computed

$$
\hat{f}(\mathbf{x})=b(\mathbf{x})+(1+c(\mathbf{x})) f(\mathbf{x})
$$

and instead of using $f$ in the first DIC step, the corrected reference image $\hat{f} \quad 152$ is considered. Therefore, a staggered algorithm is used to minimize $\rho_{b c c}(\mathbf{x}), \quad{ }_{153}$ namely, first minimizing $\rho_{\{v\}}(\mathbf{x})$ for given gray level corrections, and then $\mathbf{1 5 4}$ $\rho_{b c c}(\mathbf{x})$ at fixed nodal displacements $\rho_{\{v\}}(\mathbf{x})$. These two steps are repeated until $\quad \mathbf{1 5 5}$ final convergence [36]. In the present case, final convergence is still checked on 156 the maximum amplitude of the nodal displacement corrections (to become less $\quad \mathbf{1 5 7}$ than $\left.10^{-4} \mathrm{px}\right)$. All the results reported herein satisfied the convergence criterion $\quad \mathbf{1 5 8}$ in less than 200 iterations. This rather large number is due to the complexity of $\mathbf{1 5 9}$ the studied phenomenon (i.e., crack network) in comparison with the very low ${ }_{\mathbf{1 6 0}}$ displacement threshold, and the coupling between BCC and DIC steps. $\quad \mathbf{1 6 1}^{\mathbf{1 6}}$

It is worth noting that the shape functions of BCCs (Equation (11)) do ${ }_{\mathbf{1 6 2}}$ not need to be identical to those used in the kinematic basis (Equation (1)). $\quad{ }_{\mathbf{1 6 3}}$ Consequently, the scale at which the displacement field is discretized can be ${ }_{\mathbf{1 6 4}}$ different from that associated with brightness and contrast corrections. This remark shows that the present framework is adaptable to various situations. Two very different discretizations are studied hereafter.

\subsection{Correction types}

In the following analyses, three different types of gray level corrections were $\quad \mathbf{1 6 9}$ used, namely only brightness correction (B), only contrast correction (C), bright- $\quad{ }_{170}$ ness and contrast (BC) corrections. Two discretizations were used, namely one $1 \mathbf{1 7}$ 8-noded quadrilateral element (Q8) with the same size of the ROI. This Q8 172 element was used to perform gray level corrections taking into account the vari- $\quad{ }_{\mathbf{1 7 3}}$ ations of brightness and contrast over the entire surface (i.e., with eight degrees $\quad \mathbf{1 7 4}$ of freedom (DOFs) per corrected component). A fine mesh (FM) composed of ${ }_{\mathbf{1 7 5}}$ 3-noded triangular elements (T3) was used with an average size of 5 px. This 176 
mesh is made of 40,000 nodes. This second mesh was also utilized for the dis- ${ }_{\mathbf{1 7 7}}$ cretization of the displacement fields (i.e., DIC + BCCs) and for the analyses 178 with no correction (i.e., no BCC).

The fine mesh can be seen in a zoomed zone shown in Figure 1. Such mesh ${ }_{180}$ covers the whole ROI but the elements are too small to be displayed in the ${ }_{\mathbf{1 8 1}}$ reference image with no zoom. The results were designated by a tag as no BCC $\quad \mathbf{1 8 2}^{2}$ (i.e., no applied correction), and the mesh used in the correction followed by the 183 type of correction. For example, Q8 B means only brightness correction using ${ }_{\mathbf{1 8 4}}$ the 8-noded quadrilateral element.

185

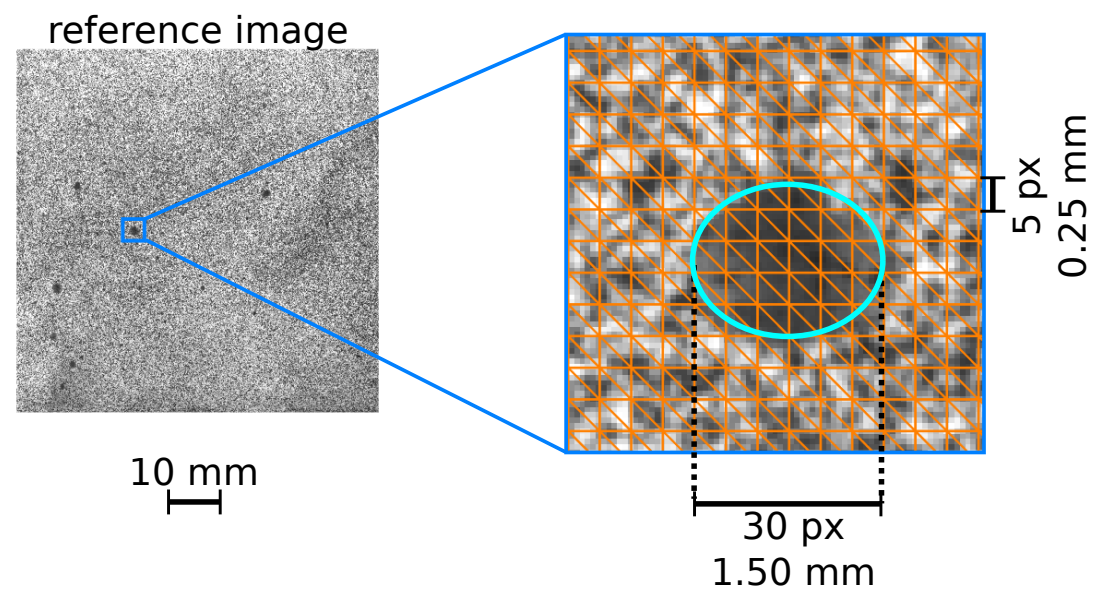

Figure 1: Reference image used in the DIC analyses with an indication of the ROI and a zoomed zone containing one open pore

The images were processed using the Correli 3.0 framework [56] in which ${ }_{\mathbf{1 8 6}}$ BCCs were implemented (Table 3). 
Table 3: DIC analysis parameters

\begin{tabular}{|l|l|}
\hline \hline DIC software & Correli $3.0[56]$ \\
Image filtering & none \\
Element length & 5 pixels \\
Mesh & linear (T3) \\
Matching criterion & regular (see Figure 1) \\
Interpolant & see text \\
Displacement noise-floor & see Table 4 \\
Strain calculation & derivative of shape functions \\
Strain noise-floor & see Table 4 \\
\hline \hline
\end{tabular}

\section{Results}

\subsection{Uncertainty quantification}

The effect of the experimental set-up in terms of gray level fluctuations and corresponding measurement uncertainties was analyzed using the image 191 set \#1. Each image was used as one reference, while the other nine as "deformed" 192 pictures. This permutation resulted in 81 pairs analyzed by applying the three 193 corrections, each one using the two discretizations as described in Section 2.4. 194

In the following, the RMS nodal residuals are reported. They correspond to ${ }_{\mathbf{1 9 5}}$ the integration of the gray level residuals $\rho_{\{v\}}$ weighted by the shape functions 196 associated with each node of the finite element mesh. They were subsequently 197 normalized by the dynamic range of the reference image for DIC with no BCC and compared to their counter-parts provided by DIC $+\mathrm{BCC}$ (i.e., $\left.\rho_{b c c}\right)$ using 199 Q8 (Figure 2(a)), or FM discretization (Figure 2(b)). If there is no effect using 200 the BCC procedure, then the data should lie on the $45^{\circ}$ line. Further, the values 201 of $\rho_{b c c}$ resulting from the two discretizations used in the BCCs are compared in 202 Figure 2(c). 203

The results for $\rho_{b c c}$ with the three corrections and the two discretizations 204 mostly lie below the $45^{\circ}$ line, thereby proving that the BCCs reduced the overall 205 
gray level residuals. This result shows that the BCC procedure is beneficial to ${ }_{206}$ the reported DIC analyses. For the Q8 element, C and BC corrections achieved 207 lower levels in comparison to B corrections (Figure 2(a)). For the FM mesh, 208 the analyses using $\mathrm{B}$ or $\mathrm{BC}$ corrections led to lower residuals than that using $\mathrm{C} \quad 209$ correction only (Figure 2(b)). This difference in general trend is confirmed in 210 Figure 2(c). Because more DOFs are available for BC corrections with respect to ${ }_{211}$ B or C, the residuals could be reduced more significantly. However, the results 212 for $\mathrm{BC}$ corrections are very close irrespective of the number of DOFs.

213

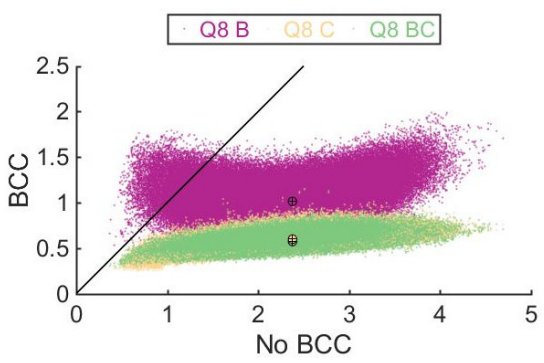

(a)

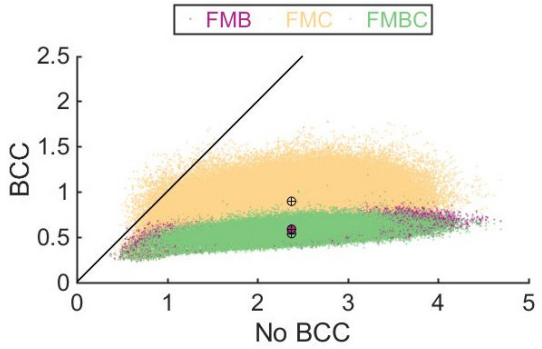

(b)

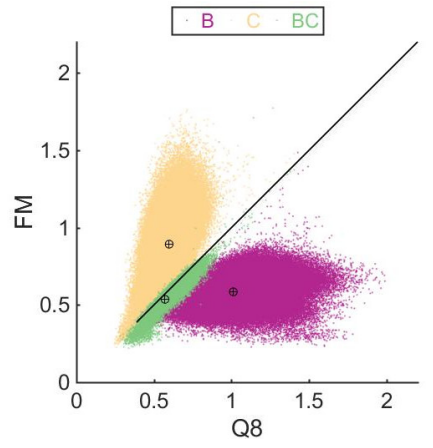

(c)

Figure 2: Normalized nodal residuals associated with $\rho_{b c c}$ (expressed in $\%$ of the dynamic range) for each type of correction: brightness (B), contrast (C), brightness and contrast (BC) compared with DIC residuals with no BCC (computed from $\rho_{\{v\}}$ ). Two different discretizations were considered in the corrections. (a) Effect of BCCs using the Q8 element, and (b) the fine mesh (FM). (c) Comparison between the results obtained with both discretizations. The circled crosses depict the mean level of each case 
In Figure 2(c), the residuals obtained with both discretizations used for ${ }_{214}$ BCCs are compared. The results are close to the $45^{\circ}$ line. The FM discretization ${ }_{215}$ performs better when applied with correction $B$ than with $C$ in which the results ${ }_{216}$ lie above the $45^{\circ}$ line. It can be a consequence of the coupling between $\mathrm{C}{ }_{217}$ corrections and the underlying kinematics because the same mesh is used for ${ }_{218}$ both of them. Besides, BC corrections performed equally well with the two ${ }^{219}$ discretizations. The fact that the residuals remain close allows the global BCC 220 with a single Q8 element to be validated in addition to the FM discretization. $\quad 221$

The same comparison procedure and permutation of images of set \#1 was 222 used to study the standard displacement uncertainties, which are reported in ${ }_{223}$ Figure 3.

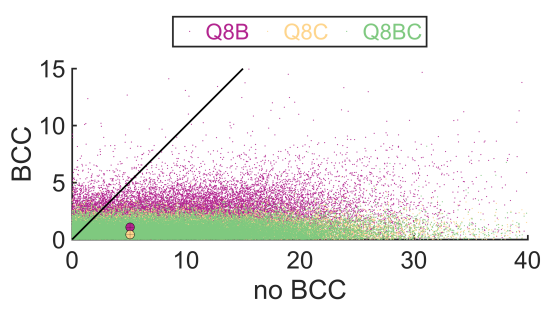

(a)

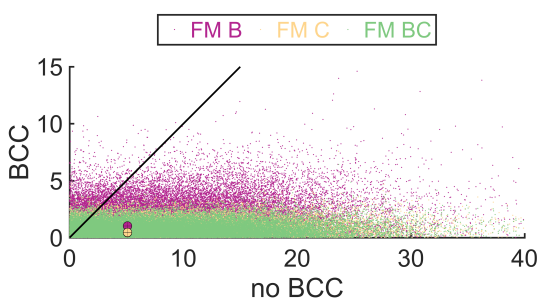

(b)

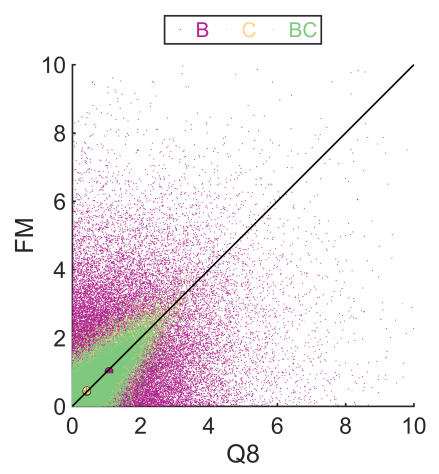

(c)

Figure 3: Standard nodal displacement uncertainty (expressed in cpx) for each correction: brightness (B), contrast (C), as well as brightness and contrast (BC). The corrections were applied using different discretizations: (a) Q8 element and (b) fine mesh (FM). (c) Comparison between the two discretizations. The circled crosses depict the mean level of each case 
Only the horizontal component of the nodal displacements is reported since the $\quad \mathbf{2 2 5}$ same levels were found for the vertical component. The small level is a result 226 of acquiring the images at the very beginning of the experiment, before crack ${ }_{227}$ network initiation (i.e., it allows for an estimation of the noise-floor levels). Fur- 228 ther, the short time intervals (i.e., $10 \mathrm{~s}$ ) between acquisitions reduce the amount $\quad 229$ of drift that may occur. Thus, in addition to acquisition noise, brightness dif- ${ }_{230}$ ferences (due to illumination variations) are the main source of displacement ${ }_{231}$ fluctuations for image set \#1. The standard deviation of each nodal displace- ${ }^{232}$ ment was computed thanks to the 81 analyses, and then it was averaged over ${ }_{233}$ all considered nodes for various corrections.

Figures $3(\mathrm{a}, \mathrm{b})$ show that there is a significant reduction (i.e., one order of ${ }_{235}$ magnitude) in standard displacement uncertainty for any of the applied correc- ${ }^{236}$ tions and the two discretizations in comparison to DIC with no BCC. In the ${ }_{237}$ present case, the $\mathrm{C}$ and $\mathrm{BC}$ corrections are more effective than B (Figure 3(c)). $\quad 238$ Such observations apply to both discretizations. The fact that the gray level ${ }_{239}$ residuals could be reduced in addition to achieving lower displacement uncer- 240 tainties validates the $\mathrm{BCC}$ procedures in the present experimental configuration. $\quad{ }^{241}$

The case study discussed herein consists of monitoring and quantifying cracks $\quad 242$ induced by curing and drying. Therefore, the maximum principal strain field ${ }^{243}$ is one of the essential quantities to analyze since it can be related to the crack ${ }^{244}$ opening displacement $[45,48]$. With the selected elements (i.e., T3), the strains ${ }_{245}$ are uniform over each element. These values were considered with no filter- ${ }_{246}$ ing, and the in-plane principal strains were computed, of which the maximum $\quad 247$ level was selected since cracks are detected with this quantity [13]. Figure $4{ }_{248}$ shows that the general trends are very close to those observed with displace- 249 ment data (Figure 3) since strain uncertainties are proportional to displacement $\quad 250$ uncertainties [57]. 


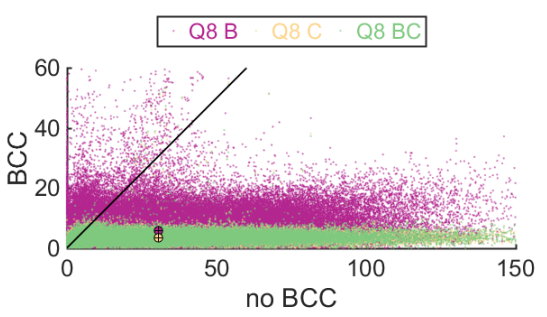

(a)

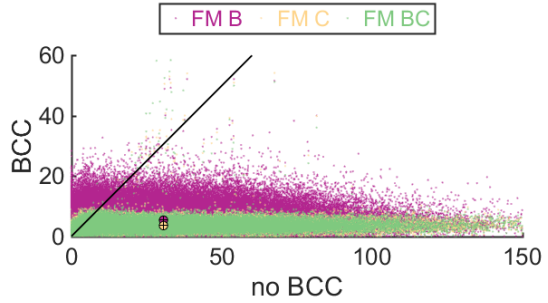

(b)

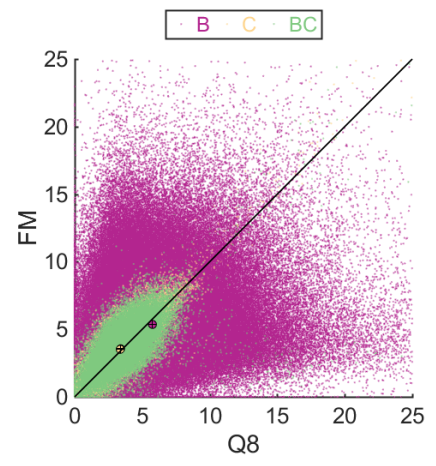

(c)

Figure 4: Standard deviation of the maximum principal strain (expressed in \%o) for each correction type: brightness (B), contrast (C), brightness and contrast (BC). The corrections were applied using different discretizations: (a) Q8 element and (b) fine mesh (FM). (c) Comparison between the two discretizations. The circled crosses depict the mean level of each case

The previous results are summarized in Table 4. For both discretizations 252 studied herein, the BC correction leads to the lowest gray level residuals. For the ${ }_{253}$ displacement and strain uncertainties, the coarse discretization provides slightly $\quad 254$ lower levels. This observation means that, in the present case, the increase in 255 DOF (FM) is irrelevant for the gray level variations, which uniformly affect the ${ }_{256}$ surface of interest, and the Q8 discretization is sufficient. The latter has a scale ${ }^{257}$ separation with the kinematic basis that will avoid couplings between the two ${ }_{258}$ steps of the registration procedure. 
Table 4: Normalized root mean square of gray level residuals $(\rho)$, standard displacement $\left(u_{x}\right)$ uncertainty, and corresponding levels for the maximum principal strain $\left(\varepsilon_{1}\right)$

\begin{tabular}{|c|c|c|c|}
\hline \hline Analyses & $\operatorname{RMS}(\rho)[\%]$ & $\operatorname{std}\left(u_{x}\right)[\mathrm{cpx}]$ & $\operatorname{std}\left(\varepsilon_{1}\right)[\%$ o $]$ \\
\hline DIC (w/ no BCC) & 2.4 & 5.1 & 30.6 \\
DIC + Q8 B & 1.0 & 1.1 & 5.8 \\
DIC + Q8 C & 0.6 & 0.4 & 3.4 \\
DIC + Q8 BC & 0.6 & 0.4 & 3.4 \\
DIC + FM B & 0.6 & 1.0 & 5.4 \\
DIC + FM C & 0.9 & 0.5 & 3.5 \\
DIC + FM BC & 0.5 & 0.4 & 3.6 \\
\hline
\end{tabular}

\subsection{Applying BCCs to curing and drying experiment}

260

The BCC procedure was applied to image set \#2 during curing and drying ${ }_{261}$ of the refractory cube. The discretizations and DIC parameters were the same ${ }_{262}$ as those used in set \#1 (Table 3 and Figure 1). The gray level residual $\rho_{\{v\}}{ }^{263}$ and maximum principal strain $\epsilon_{1}$ fields obtained with DIC with no BCC are ${ }_{264}$ shown in Figure 5 for the last acquired image of the experiment (i.e., when ${ }_{265}$ the crack network is the most developed). Both fields show the presence of ${ }_{266}$ cracks. They appear as high absolute gray levels in the residual field because ${ }_{267}$ they do not satisfy displacement continuity and new gray levels are created ${ }_{268}$ by their opening. The elements located on the cracks lead to a high value of ${ }_{269}$ maximum principal strain. Both fields are grainy, which indicates the presence 270 of fluctuations affecting them.

271 


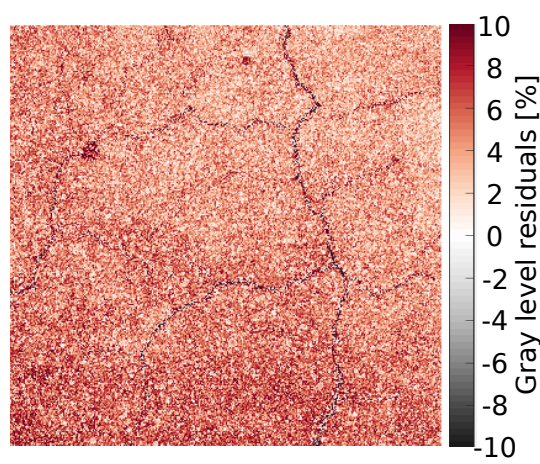

(a)

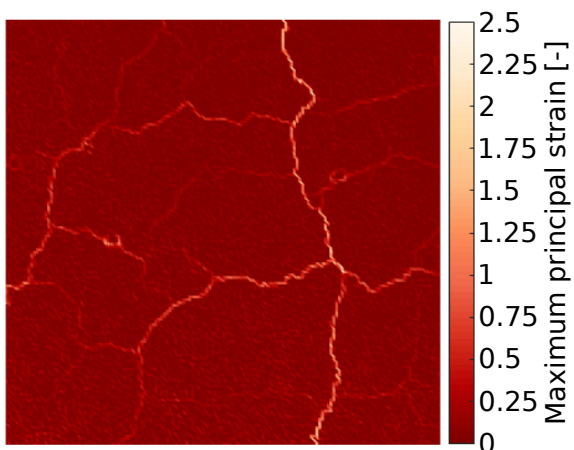

(b)

Figure 5: (a) Gray level residuals (in \% of dynamic range) and (b) maximum principal strain (dimensionless) field for the last image acquired during curing and drying of the refractory cube

Figure 6 shows the gray level residual fields $\rho_{b c c}$ when BCCs were applied. 272 The use of $\mathrm{B}$ and $\mathrm{BC}$ corrections for $\mathrm{Q} 8$ and FM discretizations significantly ${ }^{273}$ reduced the levels of the residual field, when the BCCs results are compared ${ }_{274}$ to those with no BCC (see Figure 5). The regions without cracks presented ${ }_{275}$ very low levels $\approx 0.05 \%$ (Figure $6(\mathrm{a}, \mathrm{b}, \mathrm{e}, \mathrm{f}))$. When only $\mathrm{C}$ corrections were ${ }_{276}$ applied, both Q8 and FM results induced gray level residual fields similar to 277 that provided by DIC with no BCC. These fields are very grainy, which makes 278 the larger cracks barely distinguishable (Figure 6(c,d)) for both discretizations. $\quad{ }^{279}$ 

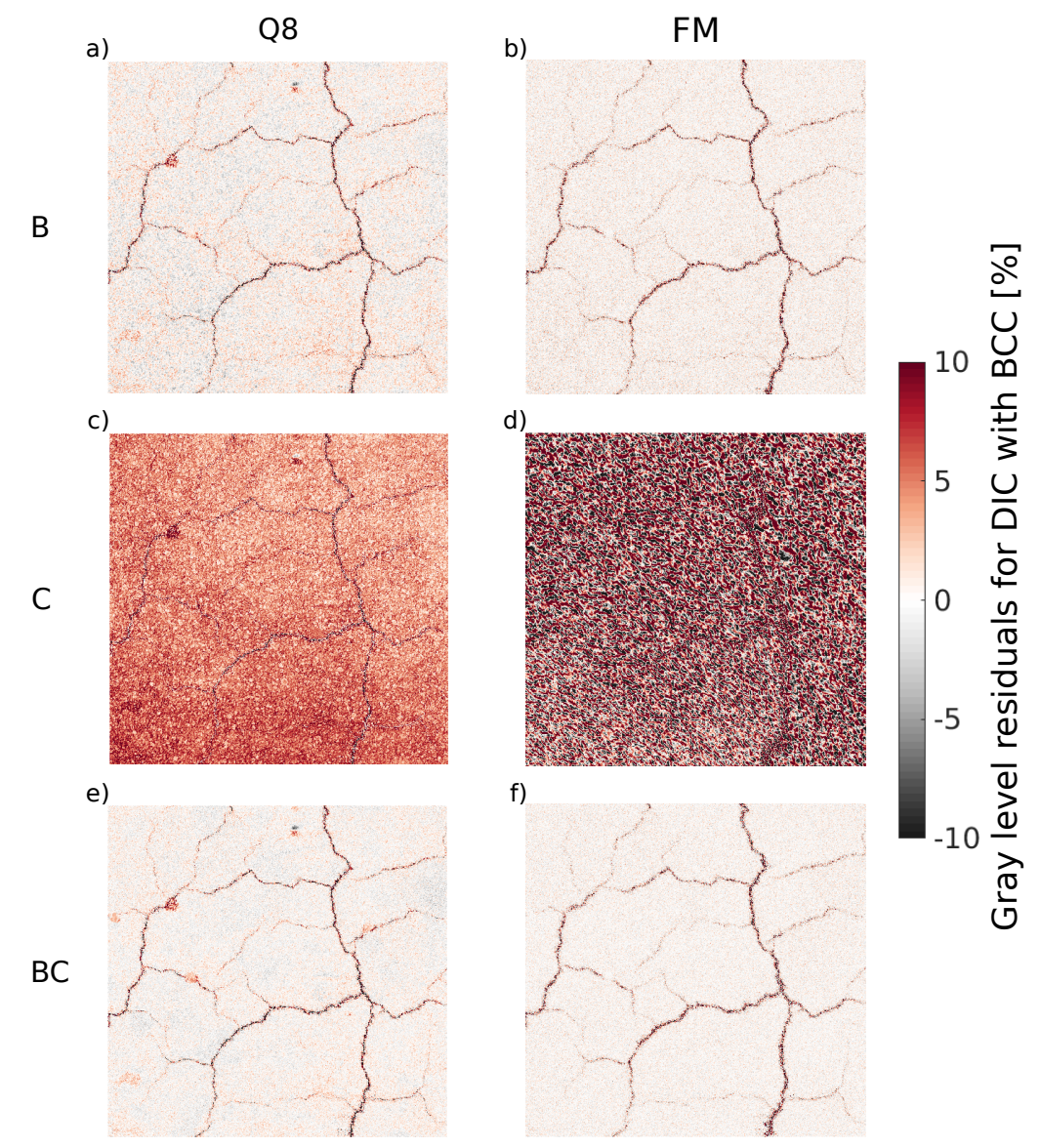

。

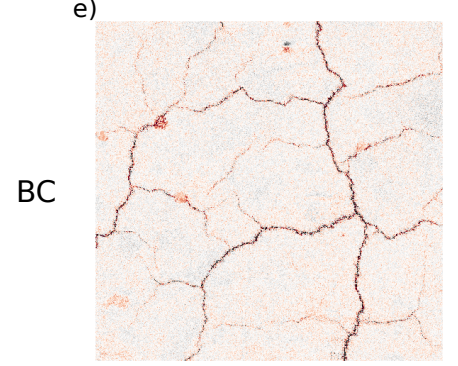

Figure 6: Normalized gray level residuals (in \% of dynamic range) for the last image captured during curing and drying when three corrections: brightness (B), contrast (C), brightness and contrast (BC) were carried out with two discretizations (Q8 and FM)

Pores are regions with low contrast, i.e., regions with uniform dark gray ${ }_{280}$ pixels due to the shadow formed by the depth of these artifacts (Figure 1), which ${ }_{281}$ may be considered as defects and corrected by the BCC procedures. Besides, ${ }^{282}$ the cracks create new gray levels during their opening, as mentioned herein, ${ }_{283}$ which makes them an additional source of gray level variation. However, the ${ }_{284}$ cracks caused by $\mathrm{MgO}$ hydration and their quantification are the main objective 285 for the present case study. If the corrections affect the detection of cracks, it is $2 \mathbf{2 8}$ important to check the effect of BCCs on their representation. One can notice ${ }^{287}$ 
that the Q8 discretization shows high values of gray level residuals in porous ${ }_{288}$ regions (i.e., $\approx 5 \%$ ), for $\mathrm{B}$ or $\mathrm{BC}$ corrections. Though, the residuals are low 289 for the same regions in the FM results $(\approx 0.5 \%)$, which means that the FM 290 can correct such effect thanks to the high number of nodes, and the element 291 size close to the pore one (Figure 1), i.e., enough DOFs (80,000 for FM BC). 292 Conversely, the FM correction spreads the gray level residuals in the cracked ${ }_{203}$ regions. It may compromise the evaluation of the crack positions. The effect ${ }_{204}$ of smeared residuals around cracks is reduced in the Q8 results because of the ${ }_{205}$ minimal number of DOFs (16 for Q8 BC) that ignores the effect of the pores, 296 and also reduces the issue in crack detection. 297

The results obtained by different BCCs are further compared using his- ${ }_{298}$ tograms of gray level residuals (Figure 7). The histograms for C corrections 299 using both discretizations are close to those with no BCC. The FM C case in- ${ }^{300}$ creased the range of gray level residuals by $\approx 30 \%$, thereby showing a lower 301 quality of the results. Such effect is due to the coupling of contrast correction 302 and the kinematic, which should be avoided [32]. The other corrections (i.e., 303 $\mathrm{B}$ and $\mathrm{BC}$ ) resulted in distributions centered about zero for both discretiza- 304 tions, which are significantly lower for the FM one. This shape is expected 305 for the standard acquisition noise, which usually is white and Gaussian as a 306 first approximation [32]. Further, there are many pixels close to zero gray level $\quad 307$ residuals that correspond to regions with no crack (i.e., clusters of aggregates). $\quad 308$ Comparing B and BC results for both discretizations, B resulted in slightly 309 wider distributions because it uses two times fewer DOFs. 310 


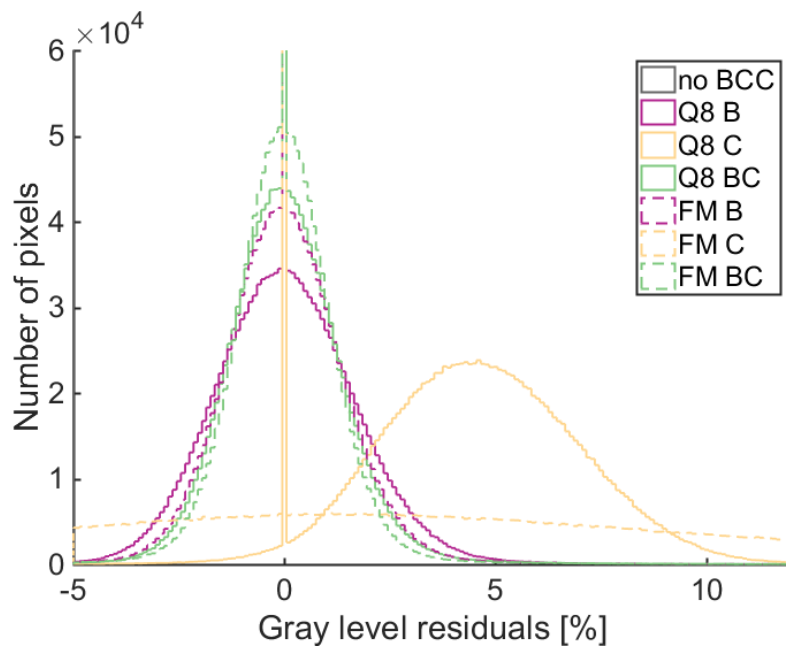

Figure 7: Histograms of gray level residuals (in \% of dynamic range) for all BCC procedures tested herein using the last image of the experiment

The frame-wise RMS of the gray level residuals is reported for the image ${ }_{\mathbf{3 1 1}}$ set \#2 (i.e., entire experiment) in Figure 8. The DIC result with no BCC 312 is related to various sources of gray level changes such as lighting and vapor ${ }_{313}$ stream. The C correction performed poorly compared to B and BC. Further, 314 the FM C analysis randomly increased the fluctuations in different frames. In 315 the present case, such corrections should not be used. Conversely, the RMS ${ }_{316}$ residuals were significantly reduced with B and BC corrections, from an average 317 RMS of $5 \%$ for DIC with no BCC to $1.5 \%$ for B and BC corrections. Last, the ${ }_{318}$ RMS levels start to increase after frame 100 for all corrections. This trend is 319 related to the opening of numerous cracks, i.e., they are one source of gray level 320 residuals even when corrections with many DOFs (FM B and FM BC) are used. 321 


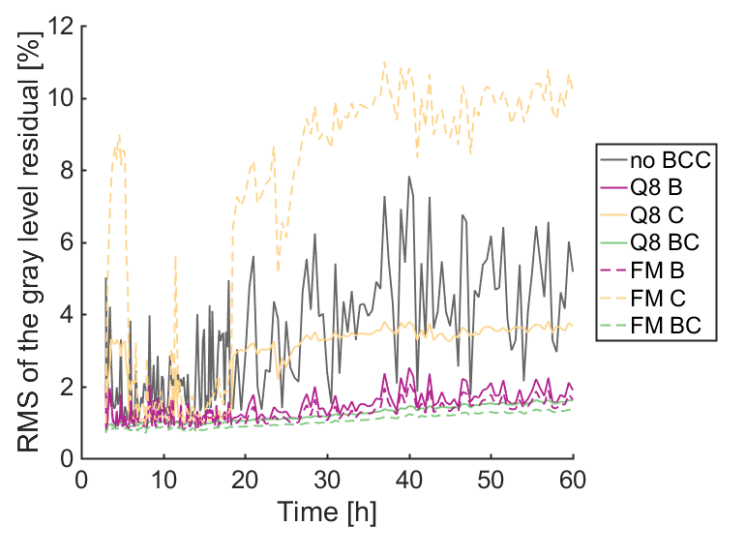

(a)

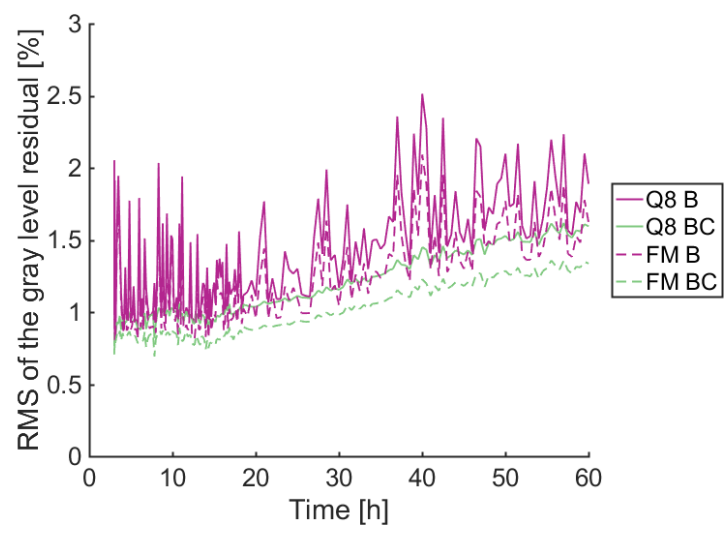

(b)

Figure 8: RMS residuals (in \% of dynamic range) for the six BCC analyses. (a) All analyses. (b) Details for the sets of parameters with smaller RMS residuals. The BCC using coarse or fine discretizations reduced the residual levels when compared to DIC with no BCC

In Figure 8(b), the three cases with higher RMS residuals (i.e., no BCC 322 and $\mathrm{C}$ corrections with both discretizations) are excluded to make easier the ${ }_{323}$ comparison between $\mathrm{B}$ and $\mathrm{BC}$ results. The $\mathrm{BC}$ correction for $\mathrm{Q} 8$ and $\mathrm{FM} \quad{ }_{324}$ reduced the residuals, and increased the difference between the results of the ${ }_{325}$ two discretizations for $\mathrm{B}$, which indicates that $\mathrm{BC}$ is more sensitive to the mesh 326 type than B. However, the mean difference of RMS residuals between B and BC ${ }_{327}$ 
corrections remains small (i.e., $\approx 0.5 \%$ of the dynamic range).

The maximum principal strain $\epsilon_{1}$ fields for the last image of the experiment (frame 200) were obtained using all BCC procedures (Figure 9).

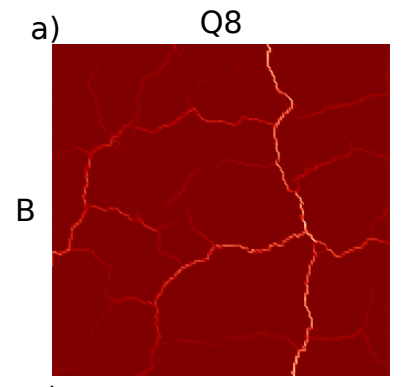

b) $\quad F M$
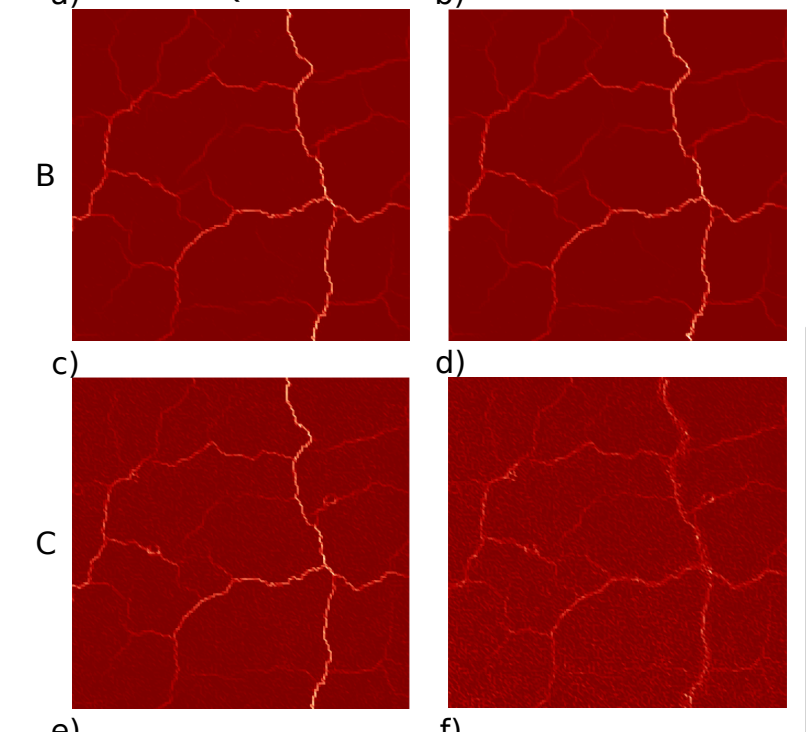

e)

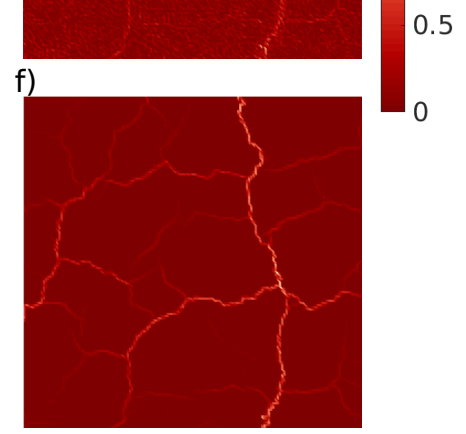

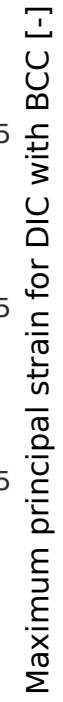

Figure 9: Maximum principal strain (dimensionless) field for the last image acquired during the experiment using the corrections: brightness $(\mathrm{B})$, contrast $(\mathrm{C})$, brightness and contrast (BC), carried out with two discretizations (Q8 and FM)

The levels of $\epsilon_{1}$ are uniform, mainly for B and BC corrections and close to zero ${ }^{331}$ in cluster regions, which is different for the grainy fields obtained using DIC ${ }_{332}$ with no BCC (see Figure 5(b)). The low strain regions are expected because ${ }_{333}$ the $\mathrm{MgO}$ hydration is a heterogeneous expansion that occurs in the matrix of the ${ }_{334}$ castable [46]. The B and BC corrections allowed small cracks to be detected (i.e., ${ }^{335}$ 
elements with low $\epsilon_{1}$ levels), which were more difficult to spot in DIC results with $\quad 336$ no BCC. Further, the effect of the pores mentioned in the gray level residuals is $3 \mathbf{3 7}$ not observed in the strain fields for the cases using the FM discretization. The $\quad 3$ latter erases spurious gray level variations caused by the pores. However, they 3 з9 may lead to higher strain levels, which would be considered as cracks in some $\mathbf{3 4 0}$ analyses, such as the crack density [48], and thereby reduce the accuracy of the $\mathbf{3 4 1}$ damage evaluation. $\quad \mathbf{3 4 2}$

The BCCs reduced not only the effect of the pores but also that one of ${ }_{\mathbf{3 4}}$ the cracks, which are localized sources of gray level changes. This phenomenon $\quad 34$ causes the appearance of elements with very small $\epsilon_{1}$ in the crack path as if the 345 BCCs tried to close the cracks. It is mainly relevant for corrections using FM 346 because this discretization has more DOFs that enable BCCs to act in localized $\quad \mathbf{3 4 7}$ segments of the surface of interest. FM C corrections resulted in a grainy field $34 \mathbf{8}$ caused by their coupling with the underlying kinematics. The FM B and FM 34 $\mathrm{BC}$ routes led to similar $\epsilon_{1}$ fields, except for the apparent wider cracks in FM $\quad 35$ $\mathrm{BC}$ and their levels smaller than the FM B results. To make the comparison 351 easier between the fields of a pair of BCCs, their differences $\Delta \epsilon_{1}$ are reported 352 in Figure $10 . \quad 353$

As the case study discussed in this paper concerns the monitoring of open $\quad \mathbf{3 5 4}$ cracks, it means that the maximum principal strain $\epsilon_{1}$ is always positive. This 355 feature is useful to distinguish the effect of each BCC by the level in the $\Delta \epsilon_{1} \quad{ }_{\mathbf{3 5 6}}$ fields of Figure 10. For example, in Q8 B - Q8BC $\Delta \epsilon_{1}$ (Figure 10(a)) the blue 357 artifacts are due to Q8 $\mathrm{BC}$, because it represents negative values in the color $\mathbf{3 5 8}$ map. These artifacts are pore effects that were better corrected by Q8 B than 359 Q8 BC. In the strain difference FM B - FM BC, no pore effect is observed 360 in Figure 10(b). However, they can be seen in red in Figures 10(c,d), and $36 \mathbf{1}$ are attributed to $\mathrm{Q} 8 \mathrm{~B}$ and $\mathrm{Q} 8 \mathrm{BC}$, respectively. These results confirm the 362 hypothesis that the FM procedures correct the pore effects, but the Q8 ones ${ }^{363}$ do not. Such feature of the FM procedures is due to the localized effect of $\mathbf{3 6 4}$ the corrections provided by the higher number of DOFs (i.e., 40,000 for B and 365 80,000 for BC corrections). 


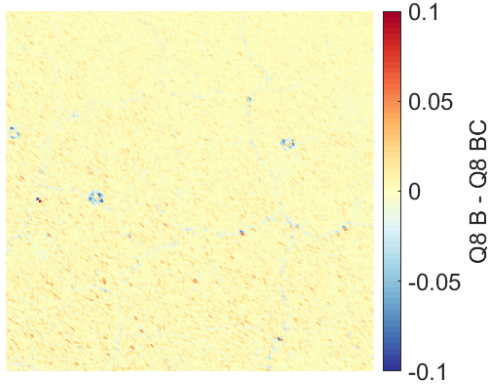

(a)

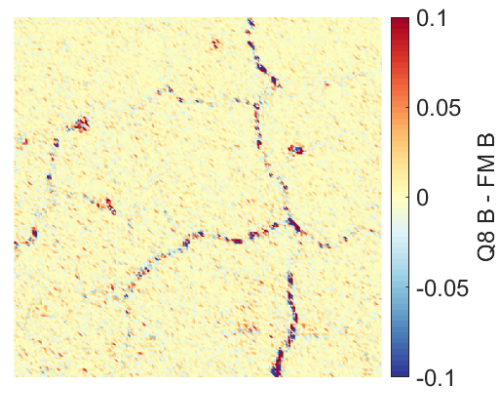

(c)

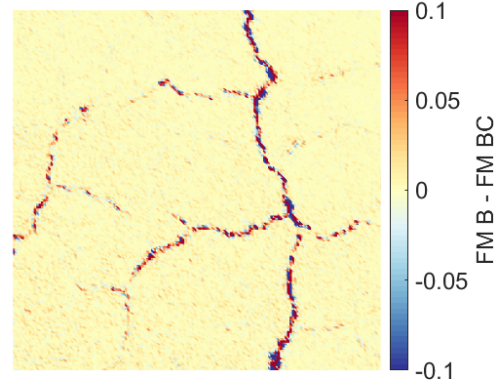

(b)

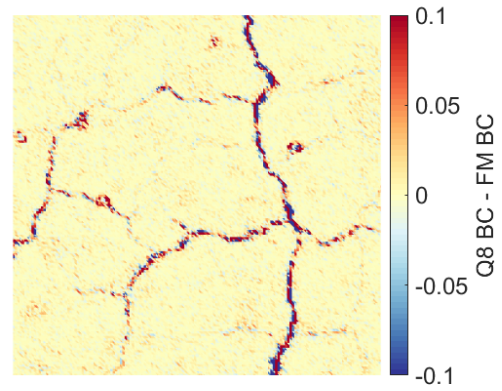

(d)

Figure 10: Difference of maximum principal strain fields $\Delta \epsilon_{1}$ (dimensionless) between: (a) Q8 $\mathrm{B}$ and Q8 BC, (b) FM B and FM BC, (c) Q8 B and FM B, and (d) Q8 BC and FM BC to show how different corrections affect the cracks. The range of the color map was reduced to improve the contrast

The effect of the BCCs on the crack opening (or equivalently on the strain ${ }_{367}$ fields) is analyzed in the sequel. In Figure 10(b), a red crack path due to FM B is mostly surrounded by blue levels provided by FM BC corrections. Red crack paths (Figures 10(c,d)) are due to Q8 corrections, which do not have a localized 370 effect, as observed for correcting the pore effects. The paths are surrounded by ${ }^{371}$ the same blue artifacts, which are due to FM B and FM BC corrections that 372 spread the grey level residuals and, consequently, reduce the $\epsilon_{1}$ levels in the ${ }^{373}$ main paths and increase it in some adjacent elements. 374

Histograms are also used to compare different distributions for the $\epsilon_{1}$ fields 375 
(Figure 11). The vertical axis is represented in logarithmic scale to make pos- $\quad{ }_{\mathbf{3 7 6}}$ sible the visualization of the number of elements with high $\epsilon_{1}$ levels. Similar to $\mathbf{3 7 7}$ the histograms obtained for the gray level residuals, the $\mathrm{C}$ corrections, mainly $\mathbf{3 7 \mathbf { 8 }}$ the FM C, are not efficient since they are close to the strain distributions of DIC 379 with no BCC. The other corrections led to distributions with a higher number $\quad 380$ of elements in low and high strains than in DIC with no BCC, i.e., there is a $\mathbf{3 8 1}$ clear separation of cluster zones $\left(\epsilon_{1} \approx 0\right)$ and cracks (high $\epsilon_{1}$ ). Moreover, the $\mathbf{3 8 2}$ distributions are very similar for B and BC corrections using both discretiza- ${ }_{38 \mathbf{3}}$ tions. Large crack openings led to deviations, mainly for the FM BC, which $\mathbf{3 8 4}$ showed fewer elements in high $\epsilon_{1}$ because this procedure has a strong localized $\quad 385$ effect and corrects the increase in gray level residuals due to cracks.

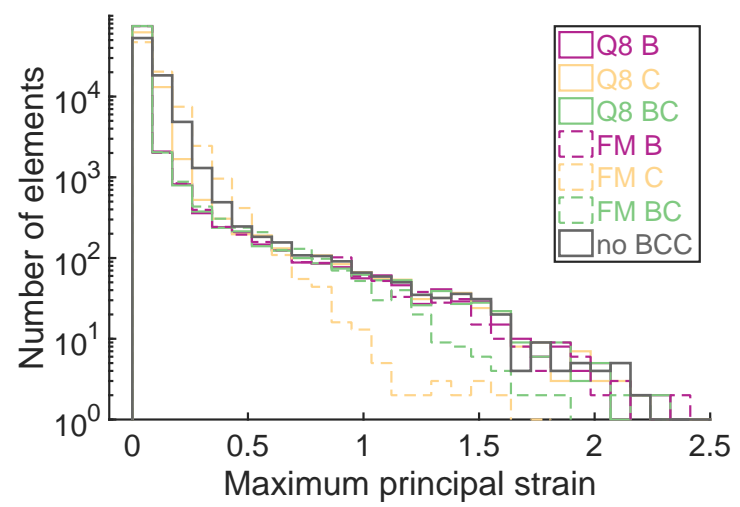

Figure 11: Histograms of maximum principal strain (dimensionless) for all BCC procedures using the last image of the experiment

The mean and standard deviation of maximum principal strains are plotted $\quad \mathbf{3 8 7}$ as a function of time (Figure 12). As expected from the previous analyses, the $\mathbf{3 8 8}$ C corrections are very close to DIC with no BCC throughout the whole history. $\quad 38$ They are fluctuating in time a lot more than the other corrections, which are 390 consistent for both reported quantities. The differences between the various 391 corrections are more important on the mean levels of $\epsilon_{1}$ than on its standard 392 
deviation. This observation proves that when the corrections are not optimal, $39 \mathbf{3}$ the mean $\epsilon_{1}$ is over-estimated.

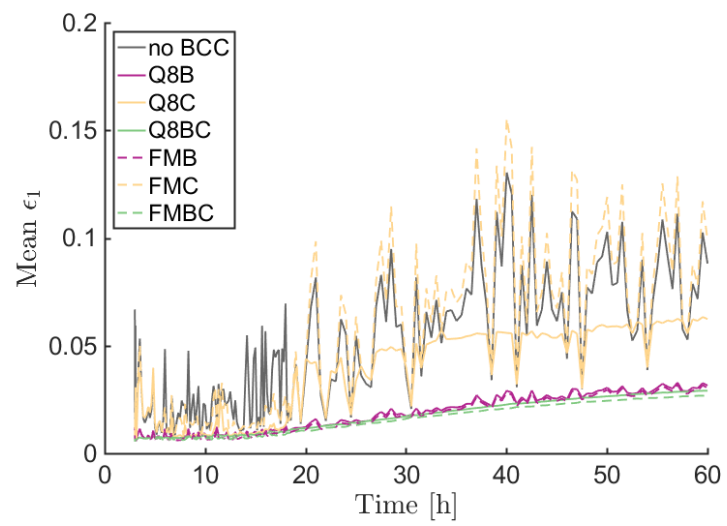

(a)

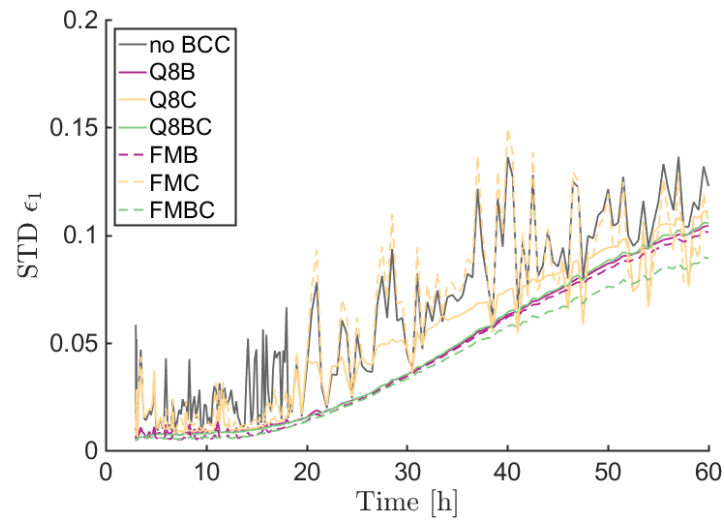

(b)

Figure 12: Evolution of mean (a) and standard deviation (b) of maximum principal strain (dimensionless) during $60 \mathrm{~h}$ of curing and drying

By considering all the previous results, it is concluded that only the con- ${ }_{\mathbf{3 9 5}}$ trast correction is not advisable as it led to results very close to those with no $\mathbf{3 9 6}$ correction at all. The brightness and contrast correction is the best type (as it 397 lowers the residuals the most) even though the brightness correction alone also 398 gave good results. The small number of DOFs required with one Q8 element 3 
A case study where a refractory cube was kept in a climatic chamber during $\quad{ }_{402}$ curing and drying was presented. Inside the chamber, the vapor stream and the ${ }_{403}$ temperature $\left(50^{\circ} \mathrm{C}\right)$ acted all over the surface of interest, thereby inducing gray ${ }_{404}$ level changes. Besides, there were two localized sources of gray level variation, ${ }_{405}$ namely, open pores on the photographed surface and cracks, which were due ${ }^{406}$ to the hydration of $\mathrm{MgO}$ present in the castable formulation. Brightness and 407 contrast corrections (BCCs) were performed in the registration, namely bright- ${ }_{408}$ ness (B), contrast (C), and brightness and contrast (BC). The BCCs made use ${ }_{409}$ of two discretizations for the same region of interest: one 8-noded quadrilateral ${ }_{410}$ element (Q8) and a fine mesh (FM with 5-px triangular elements) also used ${ }_{411}$ to measure displacement fields. The acquired images were divided into set \#1 ${ }_{\mathbf{4 1 2}}$ composed of 10 images at the beginning of the experiment (i.e., before crack ${ }^{\mathbf{4 1 3}}$ initiation), and set \#2 covering the whole experiment. Set \#1 was used to ${ }_{\mathbf{4 1 4}}$ analyze the performance of the BCCs against the effects of vapor stream and ${ }_{415}$ the temperature, whereas the goal of BCCs with set \#2 was to correct the pore ${ }_{\mathbf{4 1 6}}$ effect without compromising the crack quantification.

The uncertainty quantifications (with set \#1) showed that all BCCs were ${ }_{418}$ able to lower the gray level residuals due to experimental variations of lighting $\quad \mathbf{4 1 9}^{\mathbf{4}}$ with no cracks. BC corrections led to the lowest displacement and strain uncer- $\quad \mathbf{4 2 0}$ tainties for both discretizations, which were one order of magnitude less than ${ }^{\mathbf{4 2 1}}$ DIC results with no BCC. Conversely, B and C corrections were discretization- ${ }_{422}$ dependent. Such results highlight the gains that can be expected if such correc- ${ }^{\mathbf{4 2 3}}$ tions are implemented. $\quad \mathbf{4 2 4}^{\mathbf{4}}$

BCCs significantly reduced the gray level residuals in the presence of cracks. $\quad{ }_{\mathbf{4} 25}$ The coupling between $\mathrm{C}$ corrections and cracks made them ineffective. B and BC ${ }_{426}$ corrections resulted in maximum principal strain and gray level residual fields ${ }_{\mathbf{4 2 7}}$ with high values mostly concentrated in the cracked regions, and lower values ${ }_{\mathbf{4 2 8}}$ 
in the zones around them containing aggregate clusters. This result enabled ${ }^{429}$ the visualization of small cracks that were difficult to pinpoint via DIC with ${ }_{430}$ no BCC. The Q8 discretization should be selected to avoid interpreting pores ${ }^{431}$ as cracks because it fully decouples the very details of the kinematics from BC ${ }_{432}$ corrections. It is worth noting that finer meshes (e.g., of the characteristic size ${ }^{433}$ that of pores) but not as fine as that used for capturing the complex kinematics $\quad{ }_{434}$ induced by crack networks could also be investigated in the future to confirm ${ }_{435}$ this hypothesis.

The above discussions showed that BCCs were desirable in the case studied herein as they led to significant gains in terms of noise-floor levels and detection of very localized features (i.e., cracks). Special care should be exercised in the choice of discretization since it may lead to undesired couplings with the 440 underlying kinematics. BCCs provide additional DOFs that have to be selected ${ }_{441}$ with good understanding of the phenomena at stake in the studied experiment $\quad{ }_{442}$ (e.g., illumination conditions, image modality, kinematic basis). Once properly ${ }_{443}$ selected, they mitigate temporal fluctuations (Figure 12) that are nonphysical ${ }_{444}$ with no need for other regularization strategy.

\section{Authors' contributions}

VS, RBC, FH designed the experiments. VS performed the experiments, ${ }_{447}$ analyzed the data, and drafted the manuscript. VS, JN, FH implemented the ${ }_{448}$ computer code and supporting algorithms. RBC and $\mathrm{FH}$ provided the materials $\quad 449$ and computing resources. All authors reviewed and approved this version of the ${ }_{450}$ manuscript.

\section{Acknowledgements}

This study was financed in part by the Coordenação de Aperfeiçoamento de ${ }^{453}$ Pessoal de Nível Superior - Brasil (CAPES) - Finance Code 001. V. S. would ${ }^{454}$ also like to thank CAPES for the PDSE grant \# 8881.188511/2018-01 used ${ }_{455}$ during the internship at LMT. This study was also partially supported by the 
FAPESP-CNRS SPRINT project, grant \#2018/15266-0, São Paulo Research ${ }^{457}$ Foundation (FAPESP). The authors would like to thank prof. Victor Carlos ${ }^{458}$ Pandolfelli for the discussions about the present work.

\section{References}

460

[1] Sutton MA, McNeill SR, Helm JD, Chao YJ. Advances in ${ }^{461}$ two-dimensional and three-dimensional computer vision; vol. 77 of ${ }^{462}$ Topics in Applied Physics. 2000.

[2] Sutton MA, Orteu JJ, Schreier H. Image correlation for shape, motion and deformation measurements: Basic concepts, theory and applications. Springer Science \& Business Media; 2009.

[3] Bay B. Methods and applications of digital volume correlation. J Strain ${ }_{467}^{467}$ Analysis 2008;43:745-60.

[4] Buljac A, Jailin C, Mendoza A, Taillandier-Thomas T, Bouterf A, Neggers J, et al. Digital Volume Correlation: review on progress and challenges. Exp Mech 2018;58(5):661-708.

[5] Sutton MA. Computer vision-based, noncontacting deformation measure- ${ }_{472}$ ments in mechanics: A generational transformation. Applied Mechanics ${ }_{473}$ Reviews 2013;65(AMR-13-1009, 050802).

[6] Lyons JS, Liu J, Sutton MA. High-temperature deformation measurements 475 using digital-image correlation. Experimental Mechanics 1996;36(1):64-70. 476

[7] Sutton MA, Wolters WJ, Peters WH, Ranson WF, McNeill SR. Deter- ${ }_{477}$ mination of displacements using an improved digital correlation method. ${ }_{478}$ Image and Vision Computing 1983;1(3):133 -9.

[8] Maynadier A, Poncelet M, Lavernhe-Taillard K, Roux S. One-shot measure- ${ }_{480}$ ment of thermal and kinematic fields: Infra-red image correlation (IRIC). Experimental Mechanics 2011;52(3):241-55. 
[9] Charbal A, Roux S, Hild F, Vincent L. Spatiotemporal regularization for ${ }^{483}$ digital image correlation: Application to infrared camera frames. Interna- ${ }_{484}$ tional Journal for Numerical Methods in Engineering 2018;114(12):1331-49. $\quad{ }_{485}$

[10] Sutton MA, Li N, Joy D, Reynolds AP, Li X. Scanning Electron Microscopy ${ }^{486}$ for quantitative small and large deformation measurements part I: SEM ${ }^{487}$ imaging at magnifications from 200 to 10,000. Experimental Mechanics ${ }_{\mathbf{4 8} 8}$ $2007 ; 47(6): 775-87$.

[11] Sutton MA, Li N, Garcia D, Cornille N, Orteu JJ, McNeill SR, et al. 490 Scanning electron microscopy for quantitative small and large deformation 491 measurements part II: Experimental validation for magnifications from $200 \quad \mathbf{4 9 2}$ to 10,000. Experimental Mechanics 2007;47(6):789-804.

[12] Bay BK, Smith TS, Fyhrie DP, Saad M. Digital volume correlation: three- ${ }^{494}$ dimensional strain mapping using X-ray tomography. Experimental Me- ${ }_{495}$ chanics 1999;39:217-26.

[13] Hild F, Bouterf A, Roux S. Damage measurements via DIC. International ${ }_{497}$ Journal of Fracture 2015;191(1-2):77-105.

[14] Vargas R, Neggers J, Canto RB, Rodrigues JA, Hild F. Comparison of two ${ }^{499}$ full-field identification methods for the wedge splitting test on a refractory. $\quad \mathbf{5 0 0}$ Journal of the European Ceramic Society 2018;38(16):5569 -79. 501

[15] Vargas R, Neggers J, Canto RB, Rodrigues JA, Hild F. Analysis of a ${ }_{502}$ castable refractory using the wedge splitting test and cohesive zone model. $\quad{ }_{503}$ Journal of the European Ceramic Society 2019;39(13):3903-14. ${ }_{504}$

[16] Chevalier L, Calloch S, Hild F, Marco Y. Digital image correlation used to ${ }_{505}$ analyze the multiaxial behavior of rubber-like materials. European Journal $\quad{ }_{506}$ of Mechanics-A/Solids 2001;20:169-87.

[17] Hild F, Raka B, Baudequin M, Roux S, Cantelaube F. Multi-scale displace- ${ }^{508}$ ment field measurements of compressed mineral wool samples by digital ${ }_{\mathbf{5 0 9}}$ image correlation. Appl Optics 2002;IP 41(32):6815-28. 
[18] Novak MD, Zok FW. High-temperature materials testing with full-field ${ }_{511}$ strain measurement: Experimental design and practice. Review of Scientific $\quad{ }_{\mathbf{5 1 2}}$ Instruments 2011;82(11):115101.

[19] Lucas BD, Kanade T. An iterative image registration technique with an ${ }_{514}$ application to stereo vision. In: 7th International Joint Conference on ${ }_{515}$ Artificial Intelligence. 1981, p. 674-9. 516

[20] Chu T, Ranson W, Sutton M, Peters W. Applications of digital-image- ${ }^{517}$ correlation techniques to experimental mechanics. Experimental Mechanics ${ }_{518}$ $1985 ; 3(25): 232-44$.

[21] Tong W. An evaluation of digital image correlation criteria for strain map- $\quad 520$ ping applications. Strain 2005;41(4):167-75.

[22] Pan B. Recent progress in digital image correlation. Experimental Me- ${ }_{522}$ chanics 2011;51:1223-1235.

523

[23] Peng B, Zhang Q, Zhou W, Hao X, Ding L. Modified correlation criterion ${ }_{524}$ for digital image correlation considering the effect of lighting variations in $\quad{ }_{\mathbf{5 2 5}}$ deformation measurements. Optical Engineering 2012;51(1):1-5. 526

[24] Kammers AD, Daly S. Digital image correlation under scanning elec- ${ }_{527}$ tron microscopy: Methodology and validation. Experimental Mechanics ${ }_{528}$ 2013;53(9):1743-61.

[25] Meyer P, Waas AM. Measurement of in situ-full-field strain maps on ce- ${ }^{530}$ ramic matrix composites at elevated temperature using digital image cor- ${ }_{531}$ relation. Experimental Mechanics 2015;55(5):795-802. 532

[26] Grant BMB, Stone HJ, Withers PJ, Preuss M. High-temperature strain ${ }_{533}$ field measurement using digital image correlation. Journal of Strain Anal- ${ }_{534}$ ysis for Engineering Design 2009;44(4):263-71.

[27] Pan B, Wu D, Xia Y. High-temperature deformation field measure- ${ }_{536}$ ment by combining transient aerodynamic heating simulation system and ${ }_{\mathbf{5 3 7}}$ 
reliability-guided digital image correlation. Optics and Lasers in Engineer- ${ }_{\mathbf{5} 3 \mathbf{8}}$ ing 2010;48(9):841-8.

[28] Archer T, Beauchene P, Huchette C, Hild F. Global digital image correla- ${ }_{540}$ tion up to very high temperatures with grey level corrections. Measurement $\quad{ }_{541}$ Science and Technology 2020;31(2):024003.

[29] Lewis JP. Fast template matching. In: Vision interface; vol. 95. 1995, p. ${ }^{543}$ $15-9$.

[30] Gao G, Yao W, Xia K, Li Z. Investigation of the rate dependence of ${ }_{545}$ fracture propagation in rocks using digital image correlation (DIC) method. $\quad{ }_{546}$ Engineering Fracture Mechanics 2015;138:146-55.

[31] Su YQ, Yao XF, Wang S, Ma YJ. Improvement on measurement accuracy 548 of high-temperature DIC by grayscale-average technique. Optics and Lasers $\quad{ }_{549}$ in Engineering 2015;75:10-6.

[32] Hild F, Roux S. Digital image correlation. In: Rastogi P, Hack E, editors. ${ }_{551}$ Optical Methods for Solid Mechanics. A Full-Field Approach. Weinheim ${ }_{552}$ (Germany): Wiley-VCH; 2012, p. 183-228.

[33] Charbal A, Vincent L, Hild F, Poncelet M, Dufour JE, Roux S, et al. ${ }_{554}$ Characterization of temperature and strain fields during cyclic laser shocks. $\quad{ }_{555}$ Quantitative InfraRed Thermography Journal 2016;13(1):1-18.

[34] Charbal A, Cinoglu I, Hild F, Roux S, Vermaak N. Stereocorrela- ${ }^{557}$ tion Formalism Considering Brightness and Contrast Effects: Applica- ${ }_{558}$ tion to Torsional Loadings. Experimental Mechanics 2020;doi:10.1007/ 559 s11340-019-00576-2.

[35] Wang Y, Charbal A, Dufour J, Hild F, Roux S, Vincent L. Hybrid multiview ${ }_{561}$ correlation for measuring and monitoring thermomechanical fatigue test. $\quad \mathbf{5 6 2}_{\mathbf{6}}$ Experimental Mechanics 2020;60(1):13-33. 
[36] Mendoza A, Schneider J, Parra E, Obert E, Roux S. Differentiating 3D tex- ${ }^{564}$ tile composites: A novel field of application for Digital Volume Correlation. $\quad{ }_{565}$ Composite Structures 2019;208:735-43.

[37] Mendoza A, Schneider J, Parra E, Roux S. The correlation framework: ${ }_{567}$ bridging the gap between modeling and analysis for 3D woven composites. $\quad{ }_{568}$ Composite Structures 2019;78:111468.

[38] Ciddor PE. Refractive index of air: new equations for the visible and near $\quad 570$ infrared. Applied optics 1996;35(9):1566-73. 571

[39] Robert L, Nazaret F, Cutard T, Orteu JJ. Use of 3D digital image correla- ${ }_{572}$ tion to characterize the mechanical behavior of a fiber reinforced refractory $\quad{ }^{573}$ castable. Experimental Mechanics 2007;47(6):761-73.

[40] Belrhiti Y, Pop O, Germaneau A, Doumalin P, Dupré JC, Harmuth H, ${ }_{575}$ et al. Investigation of the impact of micro-cracks on fracture behavior of ${ }_{576}$ magnesia products using wedge splitting test and digital image correlation. $\quad 577$ Journal of the European Ceramic Society 2015;35(2):823-9.

[41] Vargas R, Neggers J, Canto RB, Rodrigues JA, Hild F. Analysis of wedge 579 splitting test on refractory castable via integrated DIC. Journal of the $\mathbf{5 8 0}$ European Ceramic Society 2016;36(16):4309-17.

[42] Sutton MA, Zhao W, McNeill SR, Helm JD, Piascik RS, Riddell WT. ${ }^{582}$ Advances in fatigue crack closure measurement and analysis: Second Vol- ${ }_{583}$ ume; chap. Local crack closure measurements: Development of a mea- ${ }_{584}$ surement system using computer vision and a far-field microscope. West ${ }_{585}$ Conshohocken: ASTM STP 1343; 1999, p. 145-56.

[43] Rupil J, Roux S, Hild F, Vincent L. Fatigue microcrack detection with ${ }_{587}$ digital image correlation. The Journal of Strain Analysis for Engineering ${ }_{588}$ Design 2011;46(6):492-509.

[44] Benboudjema F, Mauroux T, Turcry P, Ait-Mokthar A, Deves O. Experi- ${ }_{590}$ mental analysis of drying shrinkage cracking in coating mortars by digital $\quad 59$ 
image correlation. In: Mechanics and Physics of Creep, Shrinkage, and ${ }_{592}$ Durability of Concrete: A Tribute to Zdenĕk P. Baz̆ant: Proceedings of ${ }_{593}$ the Nineth International Conference on Creep, Shrinkage, and Durabil- ${ }_{594}$ ity Mechanics (CONCREEP-9), September 22-25, 2013 Cambridge, Mas- ${ }_{595}$ sachusetts. ASCE Publications; 2013, p. 235.

[45] Saracura RGM, Canto RB, Pandolfelli VC, Schmitt N, Hild F. Surface ${ }_{597}$ crack network detection on MgO-based refractory castable by digital image $\quad{ }_{598}$ correlation. China's Refractories 2015;24(1):32-7. 599

[46] Salomão R, Pandolfelli VC. The role of hydraulic binders on magnesia 600 containing refractory castables: calcium aluminate cement and hydratable ${ }_{601}$ alumina. Ceramics International 2009;35(8):3117-24. 602

[47] ASTM C1424-15. Standard test method for monotonic compressive ${ }_{603}$ strength of advanced ceramics at ambient temperature. Tech. Rep.; ASTM 604 International; 2015.

[48] Sciuti VF, Hild F, Pandolfelli VC, Santos T, Smaniotto B, Canto RB. Dig- 606 ital Image Correlation applied to in situ evaluation of surface cracks upon $\quad 607$ curing of $\mathrm{MgO}$ containing refractory castables. Journal of the European ${ }_{608}$ Ceramic Society 2020;doi:10.1016/j.jeurceramsoc.2020.04.055. 609

[49] Leplay P, Lafforgue O, Hild F. Analysis of asymmetrical creep of a ceramic ${ }_{610}$ at $1350{ }^{\circ} \mathrm{C}$ by Digital Image Correlation. Journal of the American Ceramic ${ }_{611}$ Society 2015;98(7):2240-7. ${ }_{612}$

[50] Bayer BE. Color imaging array. 1976. US Patent 3,971,065. 613

[51] Roux S, Hild F, Berthaud Y. Correlation image velocimetry: A spectral ${ }_{614}$ approach. Applied Optics 2002;41(1):108-15.

[52] Wagne B, Roux S, Hild F. Spectral approach to displacement evalua- ${ }_{616}$ tion from image analysis. European Physical Journal Applied Physics ${ }_{617}$ $2002 ; 17: 247-52$. 
[53] Broggiato GB. Adaptive image correlation technique for full-field strain ${ }_{619}$ measurement. In: Pappalettere C, editor. Proceedings of ICEM12-12th ${ }_{620}$ International Conference on Experimental Mechanics. McGraw Hill, Lilan ${ }_{621}$ (Italy); 2004, p. 420-1.

[54] Sun Y, Pang J, Wong C, Su F. Finite-element formulation for a digital ${ }_{623}$ image correlation method. Applied Optics 2005;44(34):7357-63.

[55] Besnard G, Hild F, Roux S. "Finite-Element" displacement fields analysis ${ }_{625}$ from digital images: Application to Portevin-Le Chatelier bands. Experi- ${ }_{626}$ mental Mechanics 2006;46(6):789-803.

[56] Leclerc H, Neggers J, Mathieu F, Roux S, Hild F. Correli 3.0. 2015. ${ }_{628}$ IDDN.FR.001.520008.000.S.P.2015.000.31500.

[57] Hild F, Roux S. Comparison of local and global approaches to digital image ${ }_{630}$ correlation. Experimental Mechanics 2012;52(9):1503-19. ${ }_{6 \mathbf{3 1}}$ 